\title{
Erratum to: The fern genus Polybotrya (Dryopteridaceae) in the Atlantic Forest of Brazil, with the description of a new species
}

\section{Bianca Kalinowski Canestraro and Paulo Henrique Labiak}

Programa de Pós Graduação em Botânica, Depto. de Botânica, Universidade Federal do Paraná, C. P. 19031, 81531-980, Curitiba, PR, Brazil e-mail: bianca.kc90@gmail.com; plabiak@ufpr.br

The online version of the original article can be found at http://dx.doi.org/10.1007/s12228-015-9369-1.

\section{Erratum to: Brittonia \\ DOI 10.1007/s12228-015-9369-1}

Due to a production error, the following figures were incorrectly placed in the article and associated with the wrong captions:

Fig. 5 should be the illustration that is shown in Fig. 8.
Fig. 6 should be the illustration that is shown in Fig. 5.

Fig. 7 should be the illustration that is shown in Fig. 6.

Fig. 8 should be the illustration that is shown in Fig. 7.

The correct figures and captions are reprinted below. 


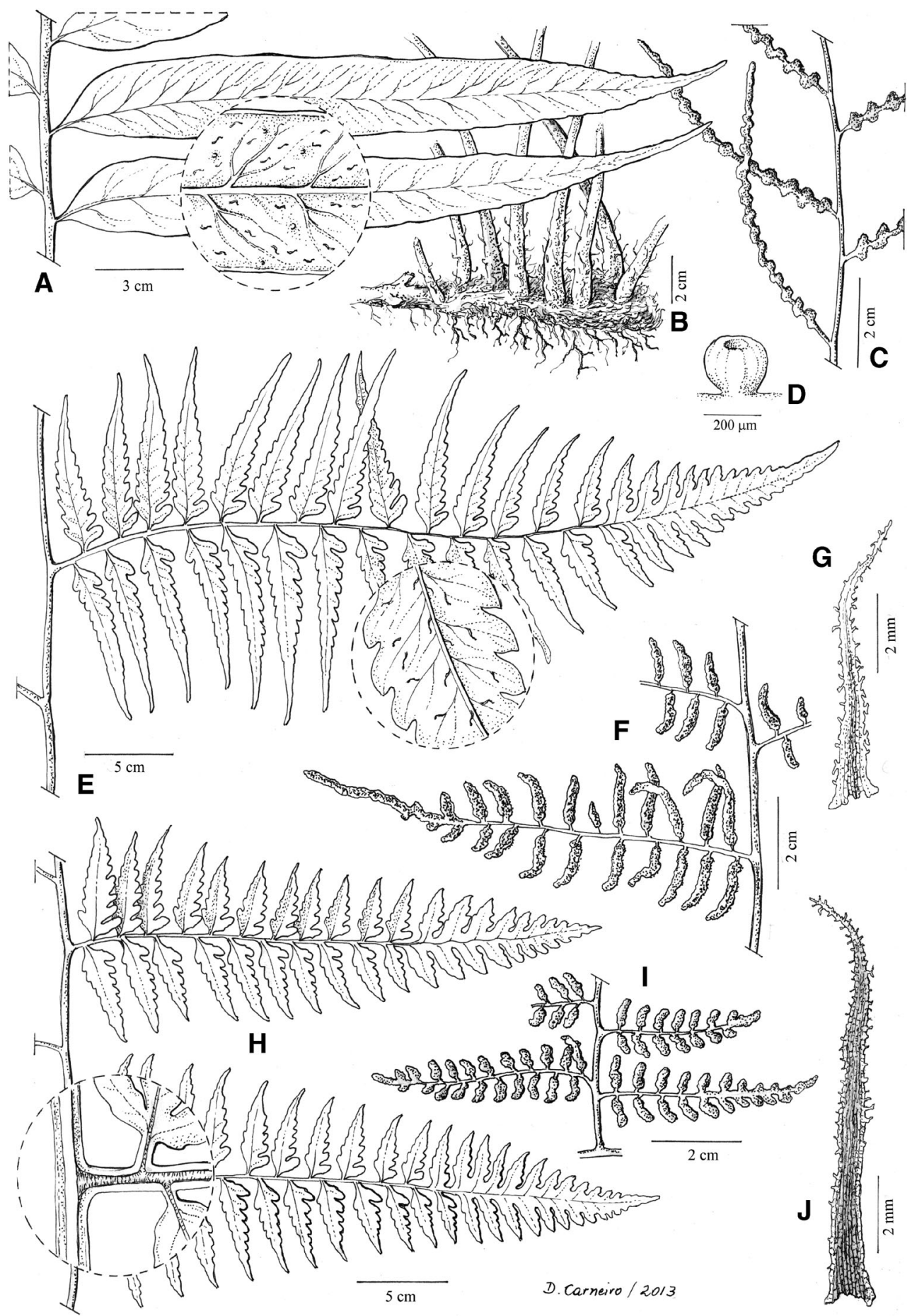

Fig. 5. A-D. Polybotrya sorbifolia. A. Detail of abaxial surface of sterile pinnae. B. Rhizome. C. Detail of fertile leaf. D. Gland on abaxial surface of sterile leaf. E-G. P. goyazensis. E. Detail of abaxial surface of sterile pinnae. F. Detail of fertile pinnae. G. Rhizome scale. H-J. P. osmundacea. H. Detail of adaxial surface of sterile pinnae. I. Detail of fertile pinnules (I from Pietrobom da Silva 4546, SP). J. Rhizome scales. (A-D from Canestraro \& Matos 530, UPCB; E from Hatschbach, 25118, MBM; F, G from Canestraro \& Matos 536, UPCB ; H-J from Pietrobom da Silva 5432, SP.) 


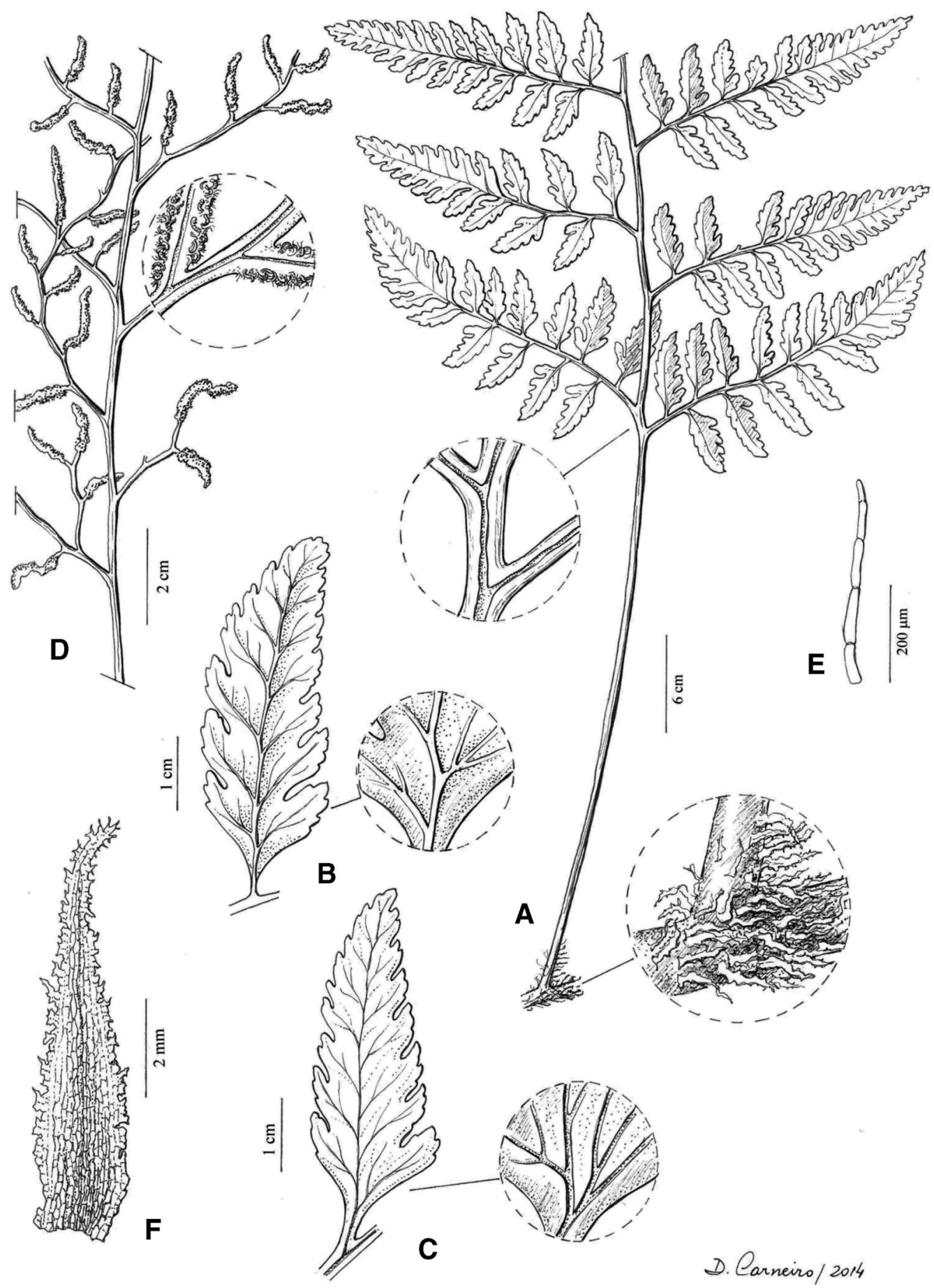

Fig. 6. Polybotrya matosii. A. Sterile leaf. B. Detail of the abaxial surface of a pinnule. C. Detail of the adaxial surface of a pinnule. D. Detail of the sori of a fertile leaf. E. Paraphyses. F. Rhizome scale. (From holotype.) 


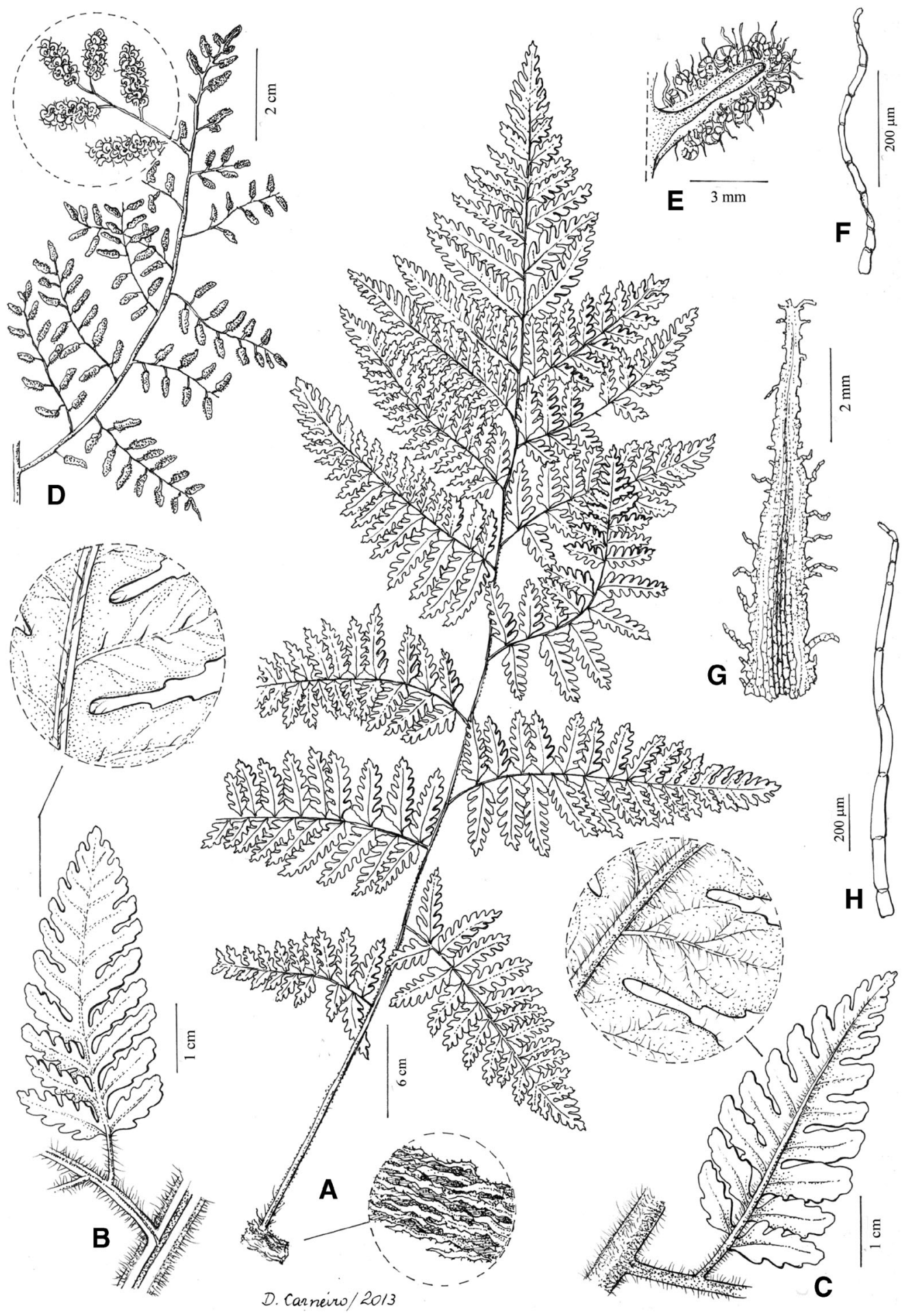

Fig. 7. Polybotrya pilosa. A. Sterile leaf. B. Detail of the adaxial surface of a pinnule. C. Detail of the abaxial surface of a pinnule. D. Detail of the sori on a fertile pinnae. E. Detail of the sori, showing sporangia and paraphyses. F. Paraphyses. G. Rhizome scale. H. Hair on the abaxial surface of a sterile leaf. (From Canestraro \& Mynssen 472, UPCB.) 


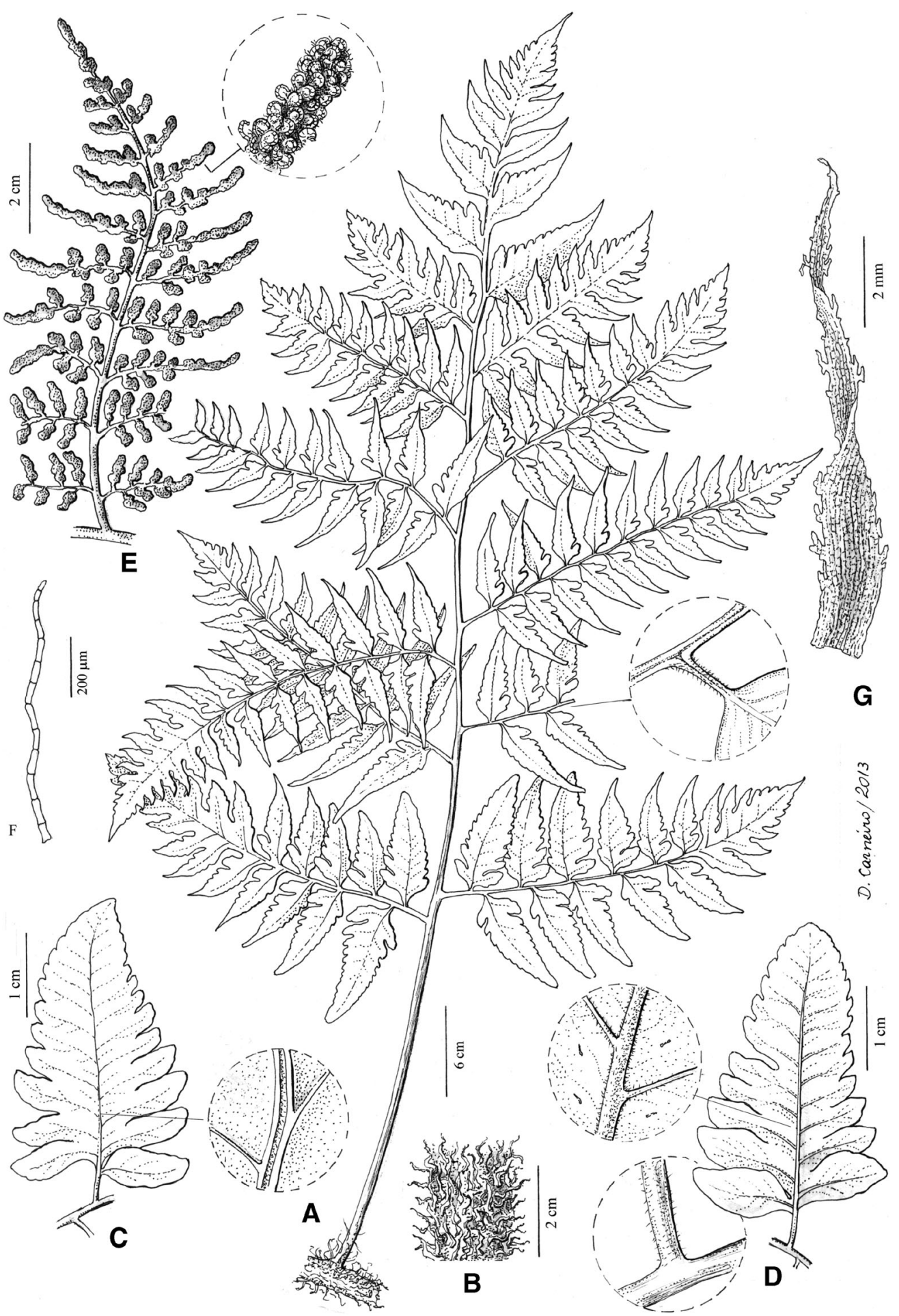

Fig. 8. Polybotrya semipinnata. A. Sterile leaf. B. Position of the rhizome scales. C. Detail of the adaxial surface of a pinnule. D. Detail of the abaxial surface of a pinnule. E. Detail of the sori on the fertile pinnae. F. Paraphyses. G. Rhizome scale. (A-D, G from Marquete 2185, RB; E-F, from Brade 12095, R.) 